\title{
Las series de televisión de máxima audiencia
}

\section{The series of primetime television}

Beatriz Peña Acuña: Universidad San Antonio. Murcia (España) beatriz-pa@gmail.com

\section{CURRÍCULUM VITAE}

Licenciada en Filología, Diplomada en Humanidades y Periodista. Profesora de "Observación sistemática y análisis de contextos" en Magisterio Infantil, "Trabajo fin de Grado" en Turismo y "Comunicación interna” a posgrados. Profesora del Cuerpo de Tutores de la Universidad Católica San Antonio. Ha participado en diversos congresos internacionales de innovación educativa como International Conference of Education and Innovation e International Technology, Education and Development Conference con varias ponencias en inglés y ha publicado artículos concernientes a la educación en vasrias revistas científicas. Ha publicado material para docentes de Secundaria para la editorial on-line de Santillana: profes.net. Ha publicado un manual sobre "Métodos de observación aplicados a las Ciencias Sociales y la Educación" dirigido a alumnos de Magisterio.

\section{RESUMEN}

El presente estudio intenta analizar los valores educativos que los medios difunden y las iniciativas que se han puesto en práctica para favorecer una televisión de calidad. Así, en una primera parte se examina este panorama a través del análisis descriptivo de dos series de ficción televisiva escogidas en razón de sus cotas de audiencia internacional y en España: CSI y Friends. Las dos series tienen un enfoque 
común narrativo en cuanto a los personajes. Destaca la amistad y la solidaridad en la interacción social. Se plantean temas éticos, en CSI con máxima referencia a lo profesional.

\title{
PALABRAS CLAVE
}

Televisión - Series - Prime time

\begin{abstract}
The present study attempts to analyze the educational values and broadcast media initiatives have been implemented to promote quality television. Thus, in the first part of this scenario is examined through descriptive analysis of two television drama series chosen because of their international audience ratings and Spain: CSI and Friends. The two series have a common narrative about the characters. Stresses the friendship and solidarity in social interaction. Ethical issues are raised in reference to CSI with maximum professional.
\end{abstract}

\section{KEY WORDS}

Television - Series - Prime time

\section{ÍNDICE}

1. Introducción

2. Descripción de elementos narrativos

3. Descripción de valores

4. Puntos fuertes de las series

5. Conclusiones 
6. Bibliografía

7. Notas

TEXTO:

\section{Introducción}

El presente estudio intenta analizar los valores educativos que los medios difunden y las iniciativas que se han puesto en práctica para favorecer una televisión de calidad. Así, en una primera parte se examina este panorama a través del análisis descriptivo de dos series de ficción televisiva escogidas en razón de sus cotas de audiencia internacional y en España: CSI y Friends. Se presta atención a los valores sociales positivos que afloran desde una vertiente ética, a los factores que determinan su éxito.

La elección de estas dos series, CSI y Friends, ha venido determinada por sus cotas de máxima audiencia. Las muestras analizadas son 10 capítulos de cada serie. La de Friends nos consta que son los capítulos preferidos de la audiencia. Esta serie comienza en 1994 y todavía tiene vigencia en la televisión en la actualidad (2009). CSI comienza más tarde en el año 2000 y también se sigue pasando como serie favorita en la televisión hoy en día. Las de CSI abarcan las tres formas Miami, Las Vegas y Nueva York. En concreto son: CSI Miami 3 capítulos de la primera temporada, CSI Las Vegas 6 capítulos de la tercera temporada, y CSI NY 1 capítulo de la tercera temporada (Nota1). 


\section{Descripción de elementos narrativos}

Las dos series tienen un enfoque común narrativo en cuanto a los personajes. La fórmula parece tener éxito en algunas series televisivas actuales. En cada capítulo se subraya un miembro del grupo porque le sucede algo a él o el hecho delictivo le toca de cerca por tratarse de un amigo, de un conocido o de un familiar. A lo largo de la serie se conoce más a cada uno de los protagonistas. Se trata de una serie que explota la psicología de los personajes, o desarrolla un guión de personajes como lo hacen otras, por ejemplo, otra serie de éxito: Perdidos (Lost) que comienza en 2001.

Los ámbitos de encuentro son muy diferentes: Friends es en un ámbito familiar íntimo, dos pisos o un sitio público donde (un bar) donde trabaja una de ellas; CSI: siempre se encuentran en el escenario del crimen, y después en un ámbito profesional: en los laboratorios de policía. Friends es una serie cómica y CSI es una serie detectivesca y melodramática.

\section{Descripción de valores}

Destaca la amistad y la solidaridad en la interacción social. En Friends la amistad se plantea entre seis personajes durante la década profesional primera, tienen unos sobre 30 años. Los lazos de amistad son arraigados desde la adolescencia, y por relación fraterna. Los seis amigos comparten los problemas emocionales y personales unos con otros, se sostienen. Se crean lazos fuertes a lo largo de la dinámica de la serie. Viven los sucesos de cada uno de forma comunitaria. Si planteamos algún defecto en la interacción es que son demasiado cotillas, y se inmiscuyen a veces demasiado en los asuntos de los demás. 
En CSI hay una relación muy buena de compañerismo y amistad por un trabajo de equipo muy arriesgado. Son policías, corren riesgos en la investigación, y son amenazados por casos antiguos que han resuelto.

En ambas plantean temas éticos, pero es más clara la referencia ética objetiva del CSI porque precisamente la finalidad de la investigación es encontrar la verdad de lo que ha sucedido, y subordinar los prejuicios, sospechas y pasiones sobre esta. Se presentan los hechos de forma neutra, pero para un adulto es fácil descubrir una crítica porque se ven las consecuencias nefastas de una mala intención o acción en la muerte de alguien o un delito sobre él.

En la serie de Friends destacan valores individuales en referencia al grupo y en todo caso, se destaca mejor los valores sociales interactivos con referencia a la amistad. Los personajes son jóvenes profesionales que no tienen solucionado ni el ámbito afectivo, ni el profesional. Su refugio es la relación de amistad que mantienen desde que son adolescentes en una ciudad superpoblada (NY) que les desborda.

En el caso de Friends la orientación ética se plantea frecuentemente sobre conflictos afectivos y los personajes de forma positiva prefieren conseguir una relación estable. En ocasiones hay temas que resultan más ambiguos porque, o bien aparecen frivolizados (como es el tema del sexo sin referencia al amor o el compromiso) por el género de la serie que es cómico, o bien se plantea de forma relativista, y se ve el beneficio simplemente sentimental de los personajes, pero no la complejidad bioética del caso (como es el caso de Phoebes que se queda embarazada in vitro para que su hermano y cuñada puedan tener un hijo, y le implantan cuatro embriones).

En el caso de Friends no se ha observado ninguna referencia a personajes menores. En el caso de CSI hemos encontrado varios. En esta serie hay un reflejo social crítico 
actual de forma pormenorizada que refleja que las consecuencias pueden ser las peores sobre la persona, como es su muerte.

Se describe desde acciones activas no éticas que pueden prevenir, alertar, como es el caso de violencia de un menor que usa un arma para asustar a un entrenador y de forma fortuita mata a su hija pequeña. Otro caso es el consumo de alcohol por parte de menores, y realizar actividades arriesgadas para encontrar diversión ("surfear" por la autopista, darse golpes con pelotas de golf). Otro caso es la grabación por parte de un menor de material pornográfico. Otro caso es la falsificación de una menor de un carné para poder acudir a un lugar de vacaciones. Se critica que los jóvenes se diviertan con la bebida, el sexo y unos facinerosos se aprovechen del estado etílico (o la tontería) para filmar contenidos pornográficos. En este caso se contempla un asesino en serie, y se viola a dos chicas que están afectadas por el alcohol. Se ve la dificultad de dos jóvenes para acceder a la Universidad por falta de medios económicos. Uno de ellos mata a su madre y casi a su padre para conseguir el dinero del seguro.

Se describe acciones no éticas pasivas sobre menores que puede provocar miedo en el menor. Por ejemplo en la muestra se describe el secuestro de un niño, o el abandono de otro por parte de su madre. También puede ser útil como prevención contra las drogas como es el caso de exceso de drogas que provoca un neurisma mortal en un joven.

La crueldad y la violencia del crimen de forma aséptica porque se trata de policía científica que analiza el escenario del crimen, y reconstruye posteriormente todo lo que ha ocurrido hasta que hallan al culpable. Por ejemplo, aparece la violencia generada en barrios marginales donde hay dificultad de adaptación social de grupos étnicos minoritarios, casos de perversión y delito sexual, negocios legales con 
actividades o acciones no éticas, negocios ilegales, homicidios premeditados por dinero, homicidios pasional, muerte por accidente o negligencia, etc.

\section{Puntos fuertes de las series}

Esta investigación considera que los guiones son muy inteligentes. La trama, los personajes y los diálogos son el punto fuerte. Se nos familiariza con unos personajes que tienen además del aspecto profesional, una vida privada, unos sentimientos. Se describe también la interacción social entre ellos de forma divertida y con anécdotas. Se plantean cuestiones sociales muy actuales, con un lenguaje muy actual y asequible que se hace cercano al público. Todos estos rasgos contribuyen, en definitiva, al éxito de audiencia de estas series.

\section{Conclusiones}

Si se contempla la calidad de estas series, uno de sus puntos fuertes es la apuesta por que el espectador se familiarice con cada uno de los personajes en el tiempo y de las relaciones interactivas entre ellos. Son personajes atrayentes por sus virtudes o simpatía o debilidad humana, pero de alguna manera los hacen asequibles y simpáticos a la audiencia.

Otro de los aspectos que hacen atractivas estas series son los diálogos inteligentes y con chispa en Friends, y en CSI la descripción de la investigación y la resolución de los casos de forma inteligente. Asimismo, la actualidad social refleja tanto los problemas afectivo-profesionales con los que se enfrentan los jóvenes profesionales, como la causa humana del homicidio $\mathrm{u}$ homicidio involuntario por voluntad individual o de estructuras sociales de nuestra sociedad. 
Coinciden en la serie de CSI el contenido ético con el éxito de audiencia como exponente de producto de calidad. En el caso de Friends podría tener una referencia ética más clara, pero con mirada positiva, los valores centrales (la solidaridad y amistad) son importantes para los jóvenes de nuestra sociedad actual.

\section{Bibliografía}

AAVV., Comunicar valores humanos, Unión Editorial, Madrid, 2002

ALMACELLAS BERNARDÓ, Mª A., Educar con el cine, EIUNSA, Barcelona, 2004

BETTETINI G. y FUMAGALLI A., Chel che resta dei media, Franco Angeli, Milano, 1998

CAMPS, V., Los valores de la educación, Madrid, Anaya, 1994

CORTINA, A., ESCÁMEZ, J. y Pérez, E., Un mundo de valores, Valencia, Generalitat Valenciana, 1996

GRANDIO PÉREZ, M., La experiencia televisiva de la audiencia y el concepto de entretenimiento. El caso de Friends en España, Facultad de Comunicación, Universidad de Navarra, Pamplona, 2006, tesis doctoral inédita

GRISOLÍA Santiago James S. y SANMARTÍN J. (eds.), Violencia, Televisión y Cine, Ariel, Barcelona, 1998

FRONIZ, R., ¿Qué son los valores? Introducción a la axiología, México, F.C.E, 1992 
GIL, A., Valores humanos y desarrollo personal. Tutorías, Madrid, Escuela Española, 1998

MURCIA GÓMEZ, A., La educación en valores a través del cine, tesis doctoral, Universidad de Murcia, 2004 [recurso electrónico, CDRom]

LUCAS MARÍN, A. y otros, Sociología de la comunicación, ed. Trotta, Madrid, 1999

NAVAL Durán, y C. URPí Guercia C., Una voz diferente en la Educación Moral, Eunsa, Pamplona, 2001

RODRÍGUEZ LUÑO, A., Ética general, Eunsa, Pamplona, 5ª ed., 2004

SERRANO OCEJA J. A., y AGEJAS J., (eds.) Ética de la comunicación y de la información, Ariel, Barcelona, 2002.

Volver a bibliografía $\quad$ Volver al principio del artículo Volver al principio

\section{Notas}

Nota1: CSI Las Vegas Tercera Temporada 1.13 a 1.15, y 3.16 a 3.19; CSI Miami Primera Temporada 1.21 y 1.22; CSI NY Tercera temporada 